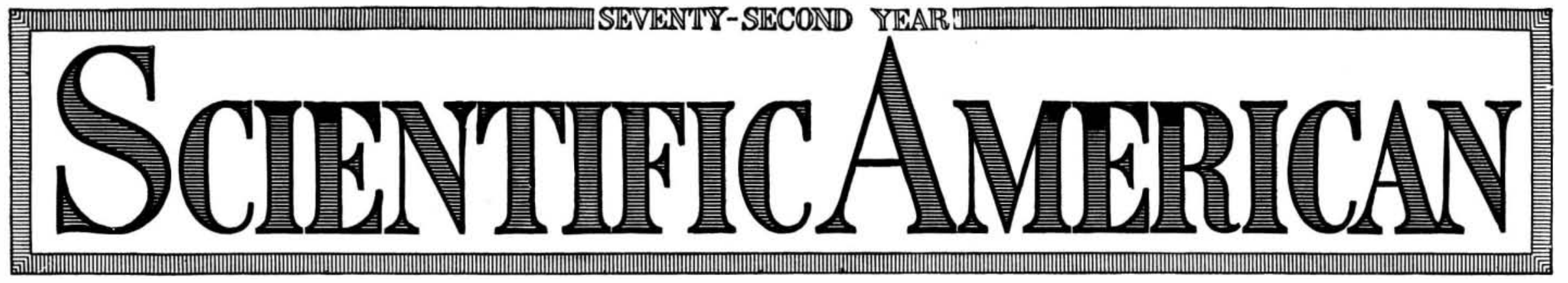

THE WEEKLY JOURNAL OF PRACTICAL INFORMATION

\section{A Difficult Piece in Subaqueous Rock Excavation} By Robert G. Skerrett

SOMEONE said a while back that national pre$N_{\text {paredness should "begin at the bottom and work }}$ upward." This critic had in mind the East River, New York, and the part it would have to play in the defense of the Atlantic seaboard in time of war. $\mathrm{He}$ also was thinking of that rast morement of oceangoing shipping that the East River seems to invit superficially and yet hampers because of submerged olistacles. Plainly, he meant that the channel fairway should be made clear for heary craft at least as far as the Navy Yard.

The biggest of our naval stations is situated on the Brooklyn side of the East Rirer. There was a time when the site was admirably suited for the purpose. To-day, this is debatable, because the ships of the battle fleet have outgrown that haven or, to be exact, the one arenue of approach and departure. Unless the tide favor, the largest of our dreadnoughts cannot safely narigate the lower reach of the East River. Our fighting craft are deeper drafted than a decade mock, and the existing channel is no longer a safe one at all times. This is because of a ledge of rock that reaches out from

the Manhattan shore and rises in the form of menacing $\mathrm{h} \mathrm{u} \mathrm{m} \mathrm{p}$ within a trifle more than 23 feet below the surface at mean low tide. $T h$ e biggest of our dreadnought and some and some of our naval c o lliers
draw 30 feet and more when full $1 \mathrm{a} \mathrm{de} \mathrm{n}$, and because of subaqueous conditions these $\mathbf{s h i p s}$ are not infrequently delayed in getting to and from the Nary Yard.

The principal stumbling block to free navigation at all hours is Coenties $R$ e e $f$. Originally, there was only 14.3 feet of water over the ledge at $\mathrm{mean}$ low tide, but the Government au. thorities cut away the rock and increased the depth 11 f e e t about 1875. Since then, ocean-going liners and the ships of the fight. ing fleet $\mathrm{h}$ a ve grown a p ce. Time a nd time a g a i n Congress was urged to cut a way more of the reef, but only recently $h$ a ve the funds been provided to strip the channel of this menace to shipping. Now, the w o $\mathbf{r}$ is under

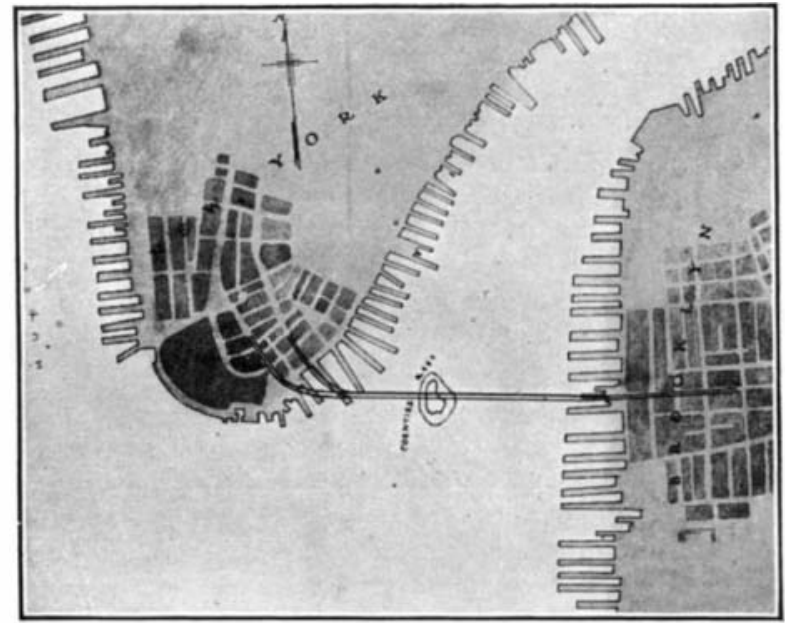

Coenties Reef and the Whitehall-Montague St. tunnels

way, and probably before a year has gone the water over. Coenties Reef at mean low tide will be not less than 40 feet. This provision will make it possible for naval craft of the deepest draft to come and go from
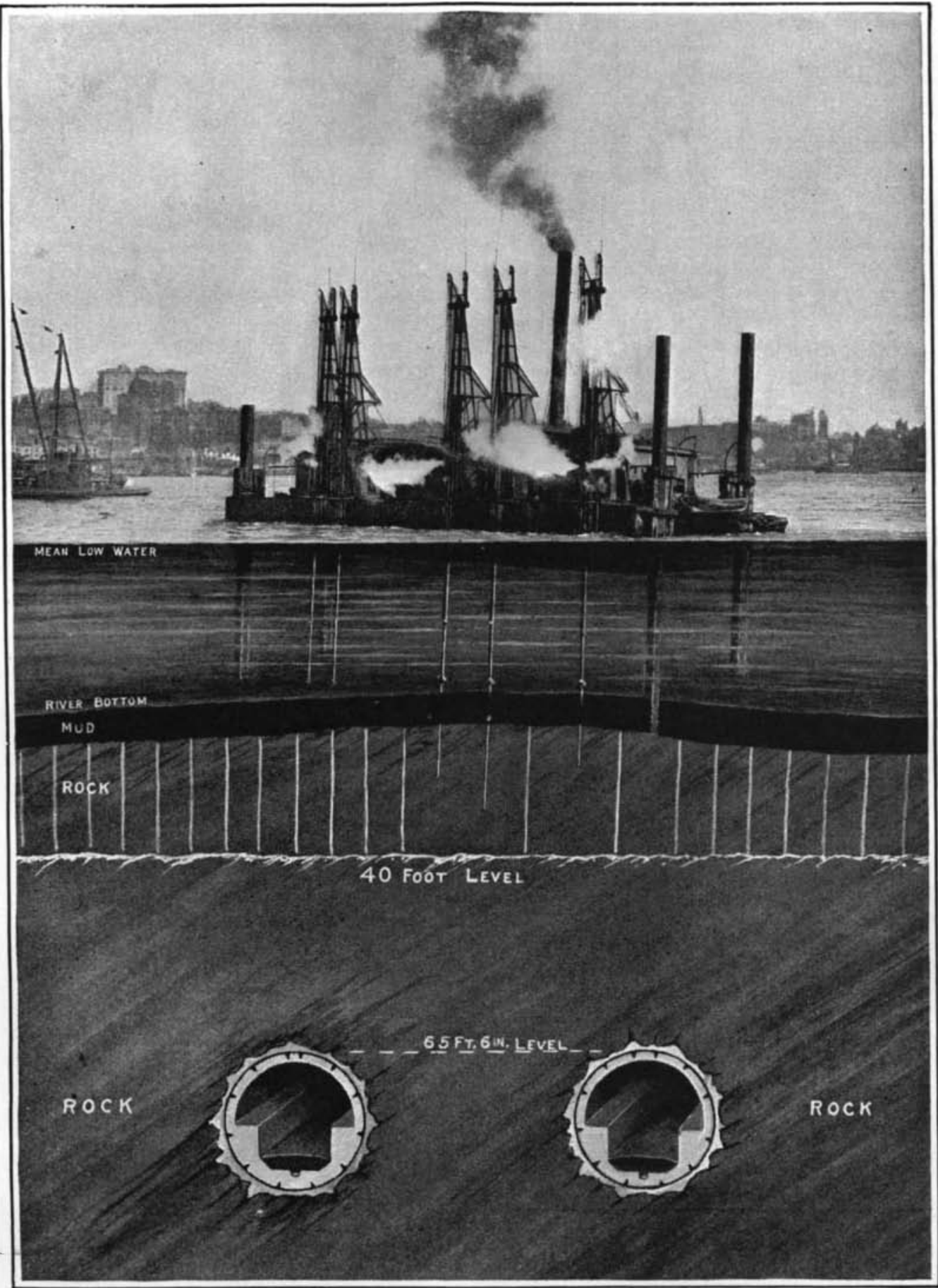

Sectional view showing the work of blasting away Coenties Reef over the new subway tunnels

the Navy Yard at any time and will make it easier and safer to maneuver the big merchantmen that now dock in the lower part of the East River.

The work to be done in order to lower the reef 15 feet will involve the removal of 28,555 cubic yards of ledge rock. The Gorernment will pay for the excavation of the first 10 feet downward and the remaining 5 -foot slice will be done at the expense of New York city. Big as the undertaking is and difficult as are the conditions, the total outlay will be only $\$ 196,900$ - such being the contract price; and this moderate charge is a matter of general interest, lecause it is the best evidence of what engineering skill has done towards facilitating the excavation of subaqueous rock. The public is probals sort is especially troublesome owing to uncertainties due to the very nature of the conditions involved; and in the present instance the contractor's task is made much harder because of the sweep of the currents and the fact that his drilling plant has to rest upon the slanting shoulder of the reef and to be held there firmly.

Again, the slicing off of Coenties Reef is not an ordinary case of the removal of under-water rock. The contractor cannot drill and blast as he commonly would

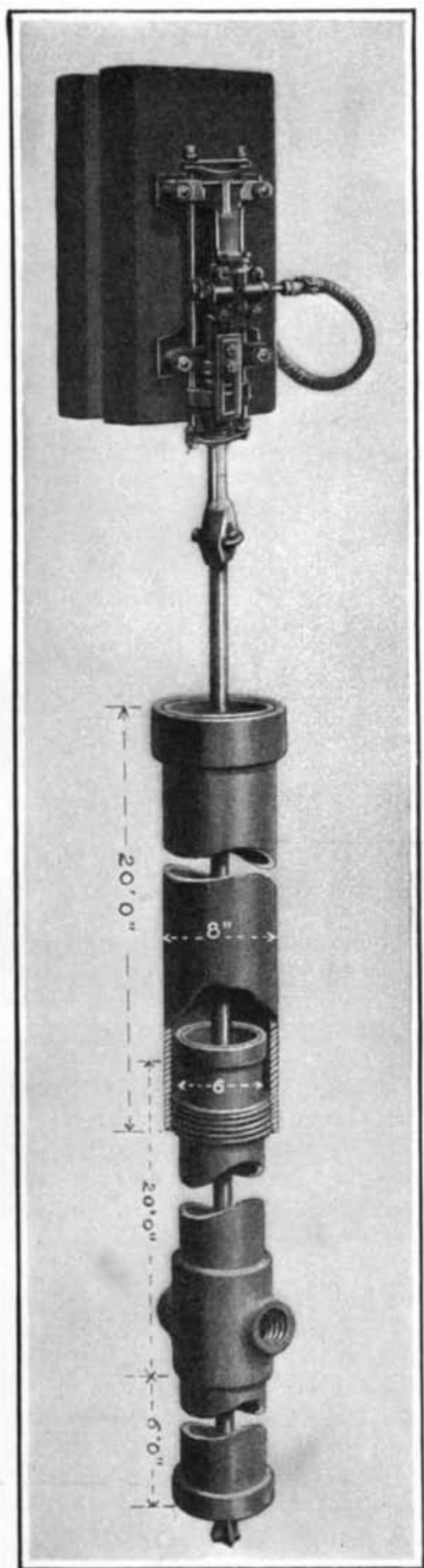

A drill and its telescoping pipe guideway if dealing with the average ledge. In this instance he has to temper his operations so as not to endanger tunnel builders, and the i work, who are engaged in driving two 18-foot passageways right through the same rocky mass but, of course, some distance below. It is the general practice for excavators of subaqueous rock to drill down 10 feet below the level of designed clear ance. The holes so bored have a diameter of about 7 inches. These holes are spaced 10 feet apart and then charged with dynamite at the rate of approximately 4 pounds per foot of depth of penetration. Of course, the quantity of dynamite is determined by the character of the rock to be blasted. W h e n the charge is de tonated the ledge is violently wracked, and the b ig wide-spaced holes suffice to break up the rock so that it can be dredged away to the desired level. In the case of Coenties Reef, the top of the page $24 \pi$ ) 
